\title{
OS SINDICATOS PODEM NEGOCIAR DIREITOS TRADICIONALMENTE INDISPONÍVEIS DOS SEUS REPRESENTADOS?
}

\section{CAN UNIONS NEGOTIATE TRADITIONALLY UNAVAILABLE RIGHTS FROM THEIR REPRESENTATIVES?}

\section{FÁBIO TÚLIO BARROSO}

Pós-Doutor em Direito pela Universidad de Granada, Espanha. Doutor em Direito pela Universidad de Deusto, Bilbao, Espanha. Especialista em Direito do Trabalho pela Universidade Católica de Pernambuco-UNICAP. Presidente Honorário e fundador da Academia Pernambucana de Direito do Trabalho - APDT. Membro Efetivo do Instituto dos Advogados Brasileiros - IAB. Membro Efetivo do Instituto de Advogados de Pernambuco - IAP. Membro Efetivo da Academia Pernambucana de Letras Jurídicas. Membro da Asociación Española de Salud y Seguridad Social AESSS. Professor da Universidade Católica de Pernambuco-UNICAP (Graduação, mestrado e doutorado). Professor da Faculdade de Direito do Recife - FDR, da Universidade Federal de Pernambuco - UFPE. Membro do Grupo de Estudos Latinoamericano de Direitos Humanos -EELAS (Registrado no CNPQ). Advogado. E-mail: fabiotulioadv@gmail.com

\section{RESUMO}

Objetivo: O objetivo da pesquisa e analisar os limites da ampliação da negociação coletiva no âmbito do Direito do Trabalho brasileiro em decorrência da edição dos arts. 611-A e 611-B da Consolidação das Leis do Trabalho, advindas da Lei ํo. $13.467 / 2017$, em especial sobre quais seriam os limites da autonomia negocial coletiva, sem olvidar-se da análise do papel do sindicato em face desse alargamento na negociação de direitos indisponíveis. 
Metodologia: Utilizou-se os métodos lógico e dedutivo, por meio de legislação trabalhista e constituional, além da revisão de literatura sobre a matéria.

Resultados: Os resultados demonstram que houve uma ampliação da autonomia negocial atribuída aos sindicatos, na medida em que conferem prevalência do negociado sobre o legislado e um alargamento da negociação coletiva entre as empresas e os empregados. Por outro acepção, conclui-se que a reforma trabalhista no aspecto negocial proporcionou risco de possíveis reduções de direitos e garantias fundamentais.

Contribuições: A contribuição deste estudo refere-se à discussão de que os sindicatos não podem negociar direitos tradicionalmente indisponíveis.Traçou-se um paralelo a respeito de como se desenvolvia a negociação sindical antes e após a edição dos arts. 611-A e 611-B da Consolidação das Leis do Trabalho, introduzidos pela Lei no. 13.467/2017, para, ao fim, após a análise de todo o complexo de normas, a principiologia do Direito do Trabalho e a doutrina especializada.

PALAVRAS-CHAVE: Reforma trabalhista; direitos indisponíveis, flexibilização.

\section{ABSTRACT}

Objective: To analyze the limits of the expansion of collective bargaining in the scope of Brazilian Labor Law due to the edition of arts. 611-A and 611-B of the Consolidation of Labor Laws, arising from Law no. 13,467/2017, in particular about what would be the limits of collective bargaining autonomy, without forgetting the analysis of the union's role in view of this enlargememt in the negotiation of unavailable rights.

Methodology: The logical and deductive methods were used through labor and constitutional legislation, as well as a literature review on the subject.

Results: The results show that there was an increase in the negotiating autonomy attributed to the unions, as they confer prevalence of the "negotiated over the legislated" and an expansion of collective bargaining between companies and employees. On the other hand, it can be concluded that the labor reform in the negotiation aspect posed the risk of possible reductions in rights and fundamental guarantees.

Contributions: The contribution of this study refers to the discussion that unions cannot negotiate traditionally unavailable rights. A parallel was drawn about how trade union negotiations developed before and after the publication of arts. 611-A and 611-B of the Consolidation of Labor Laws introduced by Law no. 13,467/2017 after the analysis of the whole complex of norms, the principles of Labor Law and the specialized doctrine. 
KEYWORDS: Labor reform; unavailable rights, relaxation.

\section{INTRODUÇÃO}

A reforma trabalhista trouxe consigo um sem-fim de controvérsias, não à toa. Uma modificação da estrutura do Direito do Trabalho foi estabelecida em regime de urgência nas casas legislativas e aprovada sem vetos pelo Poder Executivo. A oportunidade foi maior do que a acuidade no tratamento de matéria tão relevante para a sociedade brasileira e com repercussões ainda não imaginadas quando se leva em conta a importância econômica do país no cenário internacional, sobretudo, na América Latina.

Além do evidente desequilíbrio estabelecido entre os sujeitos do contrato de trabalho, seja no âmbito material ou mesmo processual, pela potencialização da autonomia da vontade e da isonomia material, respectivamente, um outro tema que permeia as vívidas discussões sobre a reforma é a ampliação dos limites da utilização da autonomia privada coletiva, sobretudo em face da criação dos artigos 611-A e 611-B da CLT, com a lei oㅜ 13.467/2017.

Sobre esta inovadora ampliação das funções representativas sindicais, as linhas vindouras são no sentido de uma reflexão sobre a finalidade da negociação coletiva e das funções sindicais diante de um novo cenário; da disponibilidade dos direitos das categorias representadas, principalmente as profissionais.

Um novo cenário se descortina em face de uma ampliação dos poderes sindicais nas negociações coletivas em um dos momentos mais difíceis da representatividade na história recente do país. Uma conjugação de inovações legislativas com possibilidade de precarização dos empregos, tendo como protagonista justamente quem deverá velar pelos direitos $e$ interesses dos trabalhadores representados: o sindicato profissional. 


\section{DA FUNÇÃO REPRESENTATIVA SINDICAL}

A constitucionalização do Direito Sindical trouxe consigo os limites das atividades das entidades associativas sindicais, total modificação do papel designado pela $\mathrm{CLT}^{1}$ antes da promulgação da carta maior. Em pelo menos dois dos oito incisos do artigo $8^{\circ}$, há determinação das funções sindicais, que, inexoravelmente estão relacionadas à sua mera atividade represententativa.

Assim, o teor dos incisos III e VI do indigitado art. 8ํㅜㄹ, a norma constitucional determina que caberá à entidade sindical representar os direitos e interesses das respectivas categorias econômicas e profissionais, seja no âmbito administrativo ou mesmo judicial, seja ainda em condições de representação individual ou coletiva. Tais funções são arrematadas, quando se faz obrigatória a participação do sindicato nas negociações coletivas, sendo forma administrativa de resolução do conflito de interesses, quando, via de regra, deverá estabelecer condições específicas de trabalho mais favoráveis do que as mínimas, sob imperativo também constitucional.

Não de difícil compreensão que a perspectiva constitucional foi que somente poderia haver a flexibilização das normas trabalhistas sob a tutela sindica $\beta$, quando de forma expressa o art. 7º, VI, XII e XIV ${ }^{4}$ estabeleceu tais condições restritivas, de modo a atingir apenas as parcelas de indisponibilidade relativa (DOS SANTOS,

\footnotetext{
${ }^{1}$ Art. 514. São deveres dos sindicatos: a) colaborar com os poderes públicos no desenvolvimento da solidariedade social; b) manter serviços de assistência judiciária para os associados; c) promover a conciliação nos dissídios de trabalho; d) sempre que possível, e de acordo com as suas possibilidades, manter no seu quadro de pessoal, em convênio com entidades assistenciais ou por conta própria, um assistente social com as atribuições específicas de promover a cooperação operacional na empresa e a integração profissional na Classe. Parágrafo único. Os sindicatos de empregados terão, outrossim, o dever de: a) promover a fundação de cooperativas de consumo e de crédito; b) fundar e manter escolas do alfabetização e pré-vocacionais.

${ }^{2}$ Art. $8^{\circ}$ E livre a associação profissional ou sindical, observado o seguinte: (...) III - ao sindicato cabe a defesa dos direitos e interesses coletivos ou individuais da categoria, inclusive em questões judiciais ou administrativas; (...) VI - é obrigatória a participação dos sindicatos nas negociações coletivas de trabalho;

3 "A Constituição brasileira de 5 de outubro de 1988 possibilitou a flexibilização de algumas de suas normas" (...), “(..) mas sempre sob tutela sindical". (SÜSSEKIND, 2001, p. 55).

${ }^{4}$ Art. 7 o São direitos dos trabalhadores urbanos e rurais, além de outros que visem à melhoria de sua condição social: (...)VI - irredutibilidade do salário, salvo o disposto em convenção ou acordo coletivo; (...)XIII - duração do trabalho normal não superior a oito horas diárias e quarenta e quatro semanais, facultada a compensação de horários e a redução da jornada, mediante acordo ou convenção coletiva de trabalho; (...)XIV - jornada de seis horas para o trabalho realizado em turnos ininterruptos de revezamento, salvo negociação coletiva;
} 
2006, p.134) pelo próprio elemento teleológico presente no caput do mesmo artigo, cuja finalidade do Direito do Trabalho é a da melhoria da condição social do trabalhador.

Dessa forma, a possibilidade de regulamentação autônoma além do conteúdo estrutural do Direito do Trabalho no país, pode implicar no afastamento do objetivo inclusivo social da disciplina jurídica e consequentemente, se tornar um elemento de precarização das condições de trabalho (BARROSO; MOURA, 2018, p.148).

Inexoravelmente, sob o manto de uma perfeita construção legislativa, as normas secundárias de um artigo deverão seguir a norma principal presente no caput do mandamento, dando-Ihe coerência e correspondência entre o conteúdo dos ditames, evitando contradições e incoerências no sistema jurídico (TAVERES FILHO, 2018). Assim, também é lógico e dedutivo, que o conteúdo do inciso XXVI do art. $7^{\circ}$ da Constituição da República impõe que o reconhecimento das convenções $e$ acordos coletivos de trabalho, somente poderá se dar em virtude de atender à melhoria da condição social do trabalhador, como corolário do princípio da norma mais favorável que é originário ao Direito do Trabalho e condizente com toda sua estrutura de mediação do conflito de classes pelo Estado, por meio da lei, na busca da pacificação social ou mesmo a mediação jurídica entre os sujeitos da relação de trabalho, no seio das sociedades capitalistas (JEAMMAUD, 1980, p.179).

Isso ocorre porque o Direito deve ser utilizado, aplicado e interpretado de forma sistemática, impedindo que casuísmos e interesses privados se sobreponham sobre o interesse público, como bem presente nos arts. $8^{\circ}$, caput ${ }^{5}$ e $444^{6}$ da CLT, sem que nenhuma modificação tenha sido implementada nos seus conteúdos com a atual reforma.

\footnotetext{
${ }^{5}$ Art. $8^{\circ}$ - As autoridades administrativas e a Justiça do Trabalho, na falta de disposições legais ou contratuais, decidirão, conforme o caso, pela jurisprudência, por analogia, por equidade e outros princípios e normas gerais de direito, principalmente do direito do trabalho, e, ainda, de acordo com os usos e costumes, o direito comparado, mas sempre de maneira que nenhum interesse de classe ou particular prevaleça sobre o interesse público.

${ }^{6}$ Art. 444 - As relações contratuais de trabalho podem ser objeto de livre estipulação das partes interessadas em tudo quanto não contravenha às disposições de proteção ao trabalho, aos contratos coletivos que lhes sejam aplicáveis e às decisões das autoridades competentes.
} 
Igualmente a isso, o respeito ao elemento teleológico do art. 623 consolidado $^{7}$ ratificou que não é possível reduzir condições sociais previstas em lei, que já são consideradas mínimas, pelo uso da autonomia privada coletiva.

Havendo fortes restrições à utilização da disponibilidade do Direito do Trabalho, como um dos seus princípios e que conforme as normas constitucionais não é possível por meio de uma forma de representação negocial designada aos sindicatos reduzir o conteúdo mínimo previsto em norma heterônoma estatal, tampouco existiria motivo algum razoável para que, por meio de procedimento negocial, aquele conteúdo mínimo de dignidade social designado pelo Estado aos trabalhadores pudesse ser objeto de reduções. Ou seja, por qual motivo se abriria uma negociação coletiva pelos sindicatos dos trabalhadores, se sabidamente a perspectiva será a de reduzir o conteúdo protetivo previsto em lei? Logo, não há razão nem mesmo lógica para se estabelecer um procedimento negocial desgastante para poder diminuir garantias sociais aos trabalhadores por meio de suas entidades representativas.

A lógica da negociação coletiva sempre foi no sentido de ampliar o conteúdo mínimo previsto em lei ${ }^{8}$, é a finalidade da norma constitucional, é a perspectiva de eficácia dos direitos fundamentais, seja em uma perspectiva vertical ou mesmo horizontal, uma vez que os Direitos Sociais estão inseridos no rol nunca taxativo destes direitos de dignidade mínima. Essa linha e racionalidade jurídica esteve presente até a nova realidade colocada pela reforma trabalhista, que permite uma ampliação do objeto da norma autônoma in pejus (NOGUEIRA, 2018, p.232).

Assim, a autonomia privada coletiva poderá ser compreendida no seu aspecto negocial como sendo uma concessão dada pelo Estado para que as

\footnotetext{
7 Art. 623. Será nula de pleno direito disposição de Convenção ou Acordo que, direta ou indiretamente, contrarie proibição ou norma disciplinadora da política econômico-financeira do Governo ou concernente à política salarial vigente, não produzindo quaisquer efeitos perante autoridades e repartições públicas, inclusive para fins de revisão de preços e tarifas de mercadorias e serviços. Parágrafo único. Na hipótese deste artigo, a nulidade será declarada, de ofício ou mediante representação, pelo Ministro do Trabalho e Previdência Social, ou pela Justiça do Trabalho em processo submetido ao seu julgamento.

${ }^{8}$ Prevalece o entendimento de que a legislação estatal estabelece condições mínimas de trabalho, não derrogáveis, em, em princípio, pelos acordos e convenções coletivas de trabalho. A norma estatal conteria, assim, garantias mínimas não derrogáveis in pejus pelas normas coletivas, mas somente substituíveis por disposições mais favoráveis. DOS SANTOS, 2009, pág. 275
} 
entidades sindicais, como interlocutores, possam dialogar e estabelecer condições de trabalho, via de regra, mais favoráveis aos trabalhadores, em obediência aos cânones constitucionais, uma verdadeiro instrumento de pacificação social, ao propiciar um constante e periódico contato entre os representantes de classe (BARROSO, 2010, p.33), como um instrumento de tutela de interesses coletivos relacionados ao grupo globalmente considerado, não se confundindo com o somatório dos interesses individuais dos membros da categoria (DOS SANTOS, 2009, p.127).

Nessa linha seja pela liberdade, seja pelos limites heterônomos no exercício desta autonomia privada coletiva conformam um setor de regulação especializado e semiautônomo ${ }^{9}$, têm como elementos finalistas nos países que adotam o regime jurídico romano-germânico a eficácia dos direitos fundamentais, evitando a desregulamentação e a imposição econômica por meios formalmente legítimos, porém, materialmente violentos.

$\mathrm{Na}$ mesma função representativa negocial e nesta perspectiva de encontros e diálogos sociais como função política da negociação coletiva, tem-se que o resultado pretendido deverá ser a formalização das fontes formais autônomas como no nosso caso; as convenções e os acordos coletivos de trabalho, em que pese o legislador não tenha determinado a obrigatoriedade desta formalização, sendo um "bem pretendido", porém, facultativo ${ }^{10}$, mas em regra, no sentido de estabelecer um bem jurídico satisfatoriamente melhor do que o mínimo já estabelecido pelo intervencionismo estatal.

\footnotetext{
${ }^{9}$ Esa constitución de la negociación colectiva con caráter normativo la sitúa como un poder privado en manos de las representaciones de trabajadore y empleadores, a quienes se le reconoce autonomia para gobernar sus propias relaciones, conformando un sector de regulación especializado y semiautónomo al que se le delega la acción económica sobre el mercado de trabajo. (MUGNOLO, 2014, p.35).

${ }_{10}$ Del estúdio de la normativa internacional se compreende que el derecho a la negociación colectiva se refiere a un proceso dinâmico que no tiene que derivar necesariamente en el convenio colectivo, $o$ cualquier outro pacto colectivo, aunque la finalidad de este proceso es alcanzar dicho acuerdo. Es decir, el derecho a la negociación colectiva abarca una actividad de negociación con una finalidade específica que consiste en convenir colectivamente pero no obliga a concluir un acuerdo colectivo; concurriendo un deber de negociar de buena fe pero no um deber de alcanzar acuerdos. (PÉREZ; JIMÉNEZ, 2014, p.935).
} 
Diante de tudo isso, a função representativa sindical se restringe a elementos conjunturais na aplicação das normas trabalhistas, ou seja, uma ampliação do conteúdo isonômico e difuso presente na legislação do trabalho, de acordo com as peculiaridades de cada categoria ao estabelecer condições específicas de trabalho, ao melhorar o conteúdo mínimo regrado ou mesmo, para criar normas de convívio pacífico e institucionalmente harmônico estre os sujeitos, ainda que tais normas criadas não estejam presentes na estrutura legislada, o que implementa o sentido da autonomia privada coletiva, uma autonomia que é via de regra capaz de disponibilizar o direito, mas no seu aspecto positivo, para se coadunar ao princípio da norma mais favorável.

Nessa exação, a função da negociação coletiva e o seu resultado positivo, na formalização das fontes formais autônomas até antes da reforma trabalhista estavam de acordo com os artigos $2^{011}$ e $5^{\circ 12}$ da Convenção nำ 154 da Organização Internacional do Trabalho - OIT, de incentivo à negociação coletiva, ratificada pelo Brasil $^{13}$, no fomento a este procedimento de diálogo político e de socialização de direitos e interesses entre os interlocutores sociais, representados pelas entidades

\footnotetext{
${ }^{11}$ Art. 2º, Convenção oํ 154 - OIT. Para efeito da presente Convenção, a expressão "negociação coletiva" compreende todas as negociações que tenham lugar entre, de uma parte, um empregador, um grupo de empregadores ou uma organização ou várias organizações de empregadores, e, de outra parte, uma ou várias organizações de trabalhadores, com o fim de: a) fixar as condições de trabalho e emprego; ou b) regular as relações entre empregadores e trabalhadores; ou c) regular as relações entre os empregadores ou suas organizações e uma ou várias organizações de trabalhadores, ou alcançar todos estes objetivos de uma só vez

12 Art. 50, Convenção no 154 - OIT. 1. Deverão ser adotadas medidas adequadas às condições nacionais no estímulo à negociação coletiva. 2. As medidas a que se refere o parágrafo 1 deste artigo devem prover que: a) a negociação coletiva seja possibilitada a todos os empregadores e a todas as categorias de trabalhadores dos ramos de atividade a que se aplique a presente Convenção; b) a negociação coletiva seja progressivamente estendida a todas as matérias a que se referem os anexos a), b) e c) do artigo 2 da presente Convenção; c) seja estimulado o estabelecimento de normas de procedimento acordas entre as organizações de empregadores e as organizações de trabalhadores; d) a negociação coletiva não seja impedida devido à inexistência ou ao caráter impróprio de tais normas; e) os órgãos e os procedimentos de resolução dos conflitos trabalhistas sejam concedidos de tal maneira que possam contribuir para o estimulo à negociação coletiva.

${ }^{13}$ I - Aprovada na $67^{a}$ reunião da Conferência Internacional do Trabalho (Genebra - 1981), entrou em vigor no plano internacional em 11.8.83. II - Dados referentes ao Brasil: a) aprovação = Decreto Legislativo n. 22, de 12.5.92, do Congresso Nacional; b) ratificação $=10.7 .92$; c) promulgação $=$ Decreto n. 1.256, de 29.9.94; d) vigência nacional = 10 de julho de 1993 (OIT, 2018b).
} 
sindicais, vislumbrando-se ainda a adequação ao teor do art. $4^{1014}$ da Convenção no 98 , igualmente ratificada pelo país ${ }^{15}$.

Isso fica muito claro, quando a norma Constitucional reconhece o conteúdo das convenções e acordos coletivos de trabalho no emprego da norma mais benéfica, consoante art. $7^{\circ}, \mathrm{XXVI}, \mathrm{c} / \mathrm{c}$ a representação sindical dos incisos III e VI do art. $8^{\circ}$, fomentando $\mathrm{o}$ diálogo entre as categorias representadas, tendo como pormenorização e peculiaridades as normas dos arts. 611 a 625 da CLT.

\section{A REFORMA TRABALHISTA E A MUDANÇA DA FUNÇÃO REPRESENTATIVA SINDICAL - AMPLIAÇÃO DOS LIMITES DA AUTONOMIA PRIVADA COLETIVA}

Mesmo sem qualquer alteração da norma constitucional, a reforma trabalhista trazida à tona por meio da lei № 13.467/2017 alterou substancialmente a função representativa sindical. Diferente do que determinam os incisos III e VI do art. $8^{\circ}$ da Constituição da República e dos estritos limites da "flexibilização sob a tutela sindical", como definido pelo saudoso mestre Süssekimd, o sentido mercadológico e competitivo do novo padrão de negociação coletiva e, por consequência das normas autônomas delas decorrentes abriram, os até então restritos limites da capacidade de o sindicato, como representante das categorias, virem a disponibilizar o direito ali representados.

O teor das normas dos artigos $611-\mathrm{A}^{16}$ e $611-\mathrm{B}^{17}$ da CLT inverteu o sentido restritivo de flexibilização do Direito do Trabalho, na sua acepção mais liberal.

\footnotetext{
${ }^{14}$ Art. 4 Convenção № 98 OIT - Deverão ser tomadas, se necessário for, medidas apropriadas às condições nacionais, para fomentar e promover o pleno desenvolvimento e utilização dos meios de negociação voluntária entre empregadores ou organizações de empregadores e organizações de trabalhadores com o objetivo de regular, por meio de convenções, os termos e condições de emprego.

${ }^{15}$ I - Aprovada na $32^{\text {a }}$ reunião da Conferência Internacional do Trabalho (Genebra - 1949), entrou em vigor no plano internacional em 18.7.51. II - Dados referentes ao Brasil: a) aprovação = Decreto Legislativo n. 49, de 27.8.52, do Congresso Nacional; b) ratificação = 18 de novembro de 1952; c) promulgação $=$ Decreto n. 33.196, de 29.6.53; d) vigência nacional = 18 de novembro de 1953 (OIT, 2018a).

${ }^{16}$ Art. 611-A. A convenção coletiva e o acordo coletivo de trabalho têm prevalência sobre a lei quando, entre outros, dispuserem sobre: I - pacto quanto à jornada de trabalho, observados os limites
} 
constitucionais; II - banco de horas anual; III - intervalo intrajornada, respeitado o limite mínimo de trinta minutos para jornadas superiores a seis horas; IV - adesão ao Programa Seguro-Emprego (PSE), de que trata a Lei no 13.189, de 19 de novembro de 2015; V - plano de cargos, salários e funções compatíveis com a condição pessoal do empregado, bem como identificação dos cargos que se enquadram como funções de confiança; VI - regulamento empresarial; VII - representante dos trabalhadores no local de trabalho; VIII - teletrabalho, regime de sobreaviso, e trabalho intermitente; IX - remuneração por produtividade, incluídas as gorjetas percebidas pelo empregado, e remuneração por desempenho individual; $X$ - modalidade de registro de jornada de trabalho; XI troca do dia de feriado; XII - enquadramento do grau de insalubridade; XIII - prorrogação de jornada em ambientes insalubres, sem licença prévia das autoridades competentes do Ministério do Trabalho; XIV - prêmios de incentivo em bens ou serviços, eventualmente concedidos em programas de incentivo; XV - participação nos lucros ou resultados da empresa. § 10 No exame da convenção coletiva ou do acordo coletivo de trabalho, a Justiça do Trabalho observará o disposto no $\S 30$ do art. 80 desta Consolidação. § $20 \mathrm{~A}$ inexistência de expressa indicação de contrapartidas recíprocas em convenção coletiva ou acordo coletivo de trabalho não ensejará sua nulidade por não caracterizar um vício do negócio jurídico. $\S 30$ Se for pactuada cláusula que reduza o salário ou a jornada, a convenção coletiva ou o acordo coletivo de trabalho deverão prever a proteção dos empregados contra dispensa imotivada durante o prazo de vigência do instrumento coletivo. $\S 40 \mathrm{Na}$ hipótese de procedência de ação anulatória de cláusula de convenção coletiva ou de acordo coletivo de trabalho, quando houver a cláusula compensatória, esta deverá ser igualmente anulada, sem repetição do indébito. $\S 50$ Os sindicatos subscritores de convenção coletiva ou de acordo coletivo de trabalho deverão participar, como litisconsortes necessários, em ação individual ou coletiva, que tenha como objeto a anulação de cláusulas desses instrumentos.

17 Art. 611-B. Constituem objeto ilícito de convenção coletiva ou de acordo coletivo de trabalho, exclusivamente, a supressão ou a redução dos seguintes direitos: I - normas de identificação profissional, inclusive as anotações na Carteira de Trabalho e Previdência Social; II - segurodesemprego, em caso de desemprego involuntário; III - valor dos depósitos mensais e da indenização rescisória do Fundo de Garantia do Tempo de Serviço (FGTS); IV - salário mínimo; V - valor nominal do décimo terceiro salário; VI - remuneração do trabalho noturno superior à do diurno; VII - proteção do salário na forma da lei, constituindo crime sua retenção dolosa; VIII - salário-família; IX - repouso semanal remunerado; $X$ - remuneração do serviço extraordinário superior, no mínimo, em $50 \%$ (cinquenta por cento) à do normal; XI - número de dias de férias devidas ao empregado; XII - gozo de férias anuais remuneradas com, pelo menos, um terço a mais do que o salário normal; XIII - licençamaternidade com a duração mínima de cento e vinte dias; XIV - licença-paternidade nos termos fixados em lei; XV - proteção do mercado de trabalho da mulher, mediante incentivos específicos, nos termos da lei; XVI - aviso prévio proporcional ao tempo de serviço, sendo no mínimo de trinta dias, nos termos da lei; XVII - normas de saúde, higiene e segurança do trabalho previstas em lei ou em normas regulamentadoras do Ministério do Trabalho; XVIII - adicional de remuneração para as atividades penosas, insalubres ou perigosas; XIX - aposentadoria; XX - seguro contra acidentes de trabalho, a cargo do empregador; XXI - ação, quanto aos créditos resultantes das relações de trabalho, com prazo prescricional de cinco anos para os trabalhadores urbanos e rurais, até o limite de dois anos após a extinção do contrato de trabalho; XXII - proibição de qualquer discriminação no tocante a salário e critérios de admissão do trabalhador com deficiência; XXIII - proibição de trabalho noturno, perigoso ou insalubre a menores de dezoito anos e de qualquer trabalho a menores de dezesseis anos, salvo na condição de aprendiz, a partir de quatorze anos; XXIV - medidas de proteção legal de crianças e adolescentes; XXV - igualdade de direitos entre o trabalhador com vínculo empregatício permanente e o trabalhador avulso; XXVI - liberdade de associação profissional ou sindical do trabalhador, inclusive o direito de não sofrer, sem sua expressa e prévia anuência, qualquer cobrança ou desconto salarial estabelecidos em convenção coletiva ou acordo coletivo de trabalho; XXVII - direito de greve, competindo aos trabalhadores decidir sobre a oportunidade de exercê-lo e sobre os interesses que devam por meio dele defender; XXVIII - definição legal sobre os serviços ou atividades essenciais e disposições legais sobre 0 atendimento das necessidades inadiáveis da comunidade em caso de greve; XXIX - tributos e outros créditos de terceiros; XXX - as disposições previstas nos arts. 373-A, 390, 392, 392-A, 394, 394-A, 395, 396 e 400 desta 
Ou seja, a lógica de que o sindicato não teria poderes para, em convenção coletiva ou acordo coletivo, pactuar a renúncia de direitos individuais dos empregados, pois no âmbito das negociações e litígios coletivos não se ventilam direitos individuais (CARRION, 2013, p.613), como um corolário de respeito aos direitos dos representados e aos princípios do Direito do Trabalho passa ser desconstruído.

É certo que o Direito necessariamente precisa se adequar à realidade dos fatos e das sociedades. Contudo, não é certo que um ramo do Direito sirva como elemento de legitimação do poder, de exacerbação da assimetria existente entre os sujeitos que precisa, por função maior e interesse público mediar, pois assim estará legitimando a violência.

Observa-se que esta modificação do sentido limitador à autonomia da vontade está diretamente relacionada à redução da função promotora social presente na legislação do trabalho, sendo uma tônica das mais variadas reformas trabalhistas que aconteceram em vários países, que traz como consequência, o fim de um modelo clássico e formal, ordinário de relações de trabalho e de liberdades condicionadas à ordem pública social ${ }^{18}$.

Fica muito evidente que o conteúdo da negociação coletiva e por conseguinte, das normas dela advindas tem uma relação direta com a imposição de um modelo econômico ortodoxo, de remercantilização ${ }^{19}$, que ao fim e ao cabo altera

Consolidação. Parágrafo único. Regras sobre duração do trabalho e intervalos não são consideradas como normas de saúde, higiene e segurança do trabalho para os fins do disposto neste artigo.

18 (...) el conjunto de valores de la vida, que por la especial transcendencia que asumen en determinado estadio de la evolución social, pasan a integrar la conciencia jurídica colectiva y se constityuen en objetos de tutela privilegiada por parte del Derecho. (...) De modo que, la materialidad fundamental del orden publico social, queda representada a través de un tríptico conformado por los seguintes valores básicos: - El trabajo no es una mercancia - El trabajo es objeto de tutela jurídica especial - La consecución de la justicia social es el criterio rector de la regulación jurídica del trabajo. (ARIGÓN, 2016, p.74).

${ }^{19}$ Lo estamos es ante un nuevo modelo de Derecho Flexible del Trabajo assentado en una intensa remercantilización del trabajo, el deterioro de los instrumentos de poder sindical y en una "acumulación por desposesión" de lo público en favor de los intereses y organizaciones privadas. (PÉREZ, 2017, p.32). 
o conteúdo ordinário designado pela disciplina jurídica aos sujeitos coletivos de trabalho e seus representados 20 e 21 .

Esta modificação do Direito do Trabalho se insere em uma ampliação do objeto negocial com limites complementares não inseridos por completo no art. 611A consolidado. Como pode ser observado da norma do caput do referido artigo: $A$ convenção coletiva e o acordo coletivo de trabalho têm prevalência sobre a lei quando, entre outros, dispuserem sobre (...). O termo "entre outros" é a chave para a disponibilização/flexibilização ampla das normas de Direito do Trabalho ${ }^{22}$ (e a ruptura do princípio da indisponibilidade e da norma mais favorável), pois, além daquelas condições ali presentes nos quinze incisos e cinco parágrafos, outras condições de trabalho não vedadas por ser "objeto ilícito" e "exclusivamente" proibida a sua negociação pelo sindicato, conforme o art. 611-B, pressupões que todas as demais normas e condições de trabalho ali não inseridas poderão ser negociadas. Um verdadeiro emprego do instrumento de eficácia horizontal dos direitos fundamentais contrario sensu ao suposto constitucional para a negociação coletiva e as consequentes normas autônomas coletivas.

Nesse aspecto, verifica-se o necessário controle deste instrumento de eficácia horizontal dos direitos fundamentais (AMARAL, 2014, p.78), visto que a ampliação dos limites da autonomia privada coletiva acaba por estabelecer possibilidades de aplicação da norma em conflito com a ordem pública social e, em consequência, um retrocesso social perpetrado justamente pela suposta ampliação da eficácia destes direitos fundamentais.

20 "La pérdida del control político sobre el orden económico globalizado transforma la función de la
regla jurídico-laboral, que se percibe ahora, en lo esencial, como un medio para moderar o para
eliminar las disposiciones limitativas al juego de las leyes ordinárias del mercado. En suma, el canon
primero de valoración de la legislación laboral ya no es o no solo es uma tutela del trabajo mismo,
sino la eficiência del mercado". DAL-RÉ, 2012, p.16. Ainda sobre as mudanças e desequilíbrios de
poderes na negociação coletiva: SILVA, 2008, p.69 e segts.
21 (...) es fácil advertir que entre aquellos factores de la economía y los mercados y la estrutura de la
negociación colectiva existe una relación de retroalimentación, puesto que, de um lado, los factores
provenientes de la economía podrían incidir en la configuración de la estructura de la negociación
colectiva y, del outro, una determinada configuración de la negociación colectiva podría incidir sobre
el desarrolllo de la economía y los mercados (CAPARRÓS; FERNÁNDEZ, 2017, p.860).
22 “(...) autoriza a supressão ou atenuação, pela negociação coletiva trabalhista, de regras imperativas
estatais incidentes sobre o contrato de trabalho, com evidente negligência à noção de centralidade da
pessoa humana na ordem jurídica e na vida social”. DELGADO; DELGADO, 2017, p.254. 
Abre-se uma brecha entre os interesses coletivos ${ }^{23}$ e os individuais, ambos privados e com identidades próprias, visto que o exercício da autonomia privada coletiva com novos horizontes e menores limites amplia o reducionismo das condições de proteção social mínimas antes designado como exceção à regra constitucional.

Assim, nesta nova realidade, não é verdadeiro que o interesse coletivo presente na negociação coletiva e representado por entidades sindicais na aplicação das normas propostas no art. 611-A consolidado seja o mesmo de antes da reforma trabalhista, como de emancipação social, que comungava com o interesse público e com o interesse privado individual de uma progressiva melhoria da condição social, como teleologia normativa e corolário do Estado Democrático de Direito, com o viés de Estado Social presente nas origens da Constituição da República, visto que a disponibilidade da aplicação da norma conforme a não taxatividade das condições presentes no caput do artigo citado e seus incisos, imprime um verdadeiro sentido contrário à ampliação dos direitos fundamentais, em evidente retrocesso social, o que por consequência se tem como inválido o conteúdo desta norma criada com a lei no $13.467 / 17$, pois impõe ao sindicato a disponibilidade de direitos $\mathrm{e}$ representação de interesses na negociação coletiva que não se coadunam com a necessária aptidão representativa até então presente.

Cria-se pois uma "polissemia de interesses" das entidades sindicais, com convicções e posições próprias em comparação com as perspectivas individuais dos representados, diante de possíveis reduções de garantias e direitos individuais até então salvaguardados nas normas heterônomas.

Como consequência, tem-se uma fratura dos interesses coletivos representados pelos sindicatos, quando se perde a condição de homogeneidade diante da perspectiva de redução das condições mínimas previstas em lei com a ampliação dos limites da autonomia privada coletiva, ao não satisfazer às necessidades de dignidade mínima da coletividade, o que não foi originalmente

${ }^{23}$ Segundo Tarello sobre o interesse coletivo: "No consiste en la suma de interesses individuales, sino en su combinación, y es indivisible, en el sentido que viene satisfecho, no ya por bienes aptos para satisfacer las necessidades individuales, sino por un único bien apto para satisfacer la necesidad de la colectividades" (TARELLO, 2002, pág. 28). 
permitido pela Constituição da República e pela estrutura do Direito do Trabalho brasileiro, e sim, uma opção política do reformista.

De igual modo, nota-se uma outra fratura no ambiente negocial, ainda que em sua expressão material e teleológica, que se apresenta por meio do princípio da fraternidade presente nas negociações coletivas e nas suas normas decorrentes ${ }^{24}$. A ruptura do compromisso social latu sensu, com a perda da obrigação com as necessidades da outra parte em manter um ambiente negocial equilibrado, seja jurídico, econômico ou social. A criação de um ambiente competitivo e de não cooperação dialógica, mas de superação pelas deficiências e dificuldades existenciais do outro.

Por sua vez, também pode gerar uma violação ao princípio da legalidade, que é inerente ao Estado Democrático de Direito, visto que, segundo o art. $5^{\circ}$ da Lei de Introdução às Normas de Direito Brasileiro, na aplicação da Lei deverão ser atendidos os fins sociais a que se dirige e às exigências do bem comum (GARCIA, 2018, p.724-725).

No âmbito da aplicação das normas internacionais no ambiente interno, em especial à aplicação da Convenção no 154 da OIT, sem dúvidas que as disposições ampliativas à flexibilização do Direito do Trabalho por meio das normas dos arts. 611-A e 611-B da CLT reformada, confrontam com a norma do seu art. $5^{\circ}$, "d", pelo caráter impróprio de tais normas, sendo um claro despropósito na ampliação dos direitos fundamentais decorrentes da relação de emprego, o que também colide com o conteúdo do art. 4ำ da Convenção ํo 98 da OIT, uma vez que fica maculado 0 pleno desenvolvimento social como movimento expansivo do Direito do Trabalho.

Ou seja, o teor das normas consolidadas modificadas precisam se coadunar com os princípios e normas nacionais e internacionais que o Brasil se obrigou, ou até mesmo às suas fontes materiais, tudo isso como elementos cogentes de tutela

${ }^{24}$ GUNTHER; VILLATORE, 2018, p.63. O pressuposto para a fundação de uma democracia encontra-se em um direito pactuado entre pessoas em igualdade de condições, sem a carga do medo e da culpa interditórios. Consideram-se, nessa medida, os indivíduos em sua capacidade de escolha, ou seja, exige-se o reconhecimento da dignidade do ser humano. Em uma comunidade fraterna os indivíduos têm em comum exatamente suas diferenças. É necessário, pois, encarar o outro segundo uma política de diferença baseada na dignidade universal do ser humano e na alteridade, onde cada indivíduo assume o ponto de vista do outro. 
ao trabalho humano (DELGADO; DELGADO, 2017, p.256-257), o que, por certo, tem-se que a ampliação da autonomia privada coletiva presente nos referidos artigos não atende, pela possibilidade de redução das garantias e direitos mínimos presentes nas normas estatais que podem ser negociadas.

Não obstante a isso e como aludido, o Direito precisa ser interpretado de forma sistemática, dando a ideia geral do que se determina e é pretendido em cada momento da história. Assim, tem-se que a potencialização da autonomia da vontade para ampliar os limites do negociado frente ao legislado, ainda que se sobrepondo às condições mínimas de trabalho previstas em lei é apenas um arremate ao que já fora anteriormente modificado nesta remercantilização do Direito do Trabalho, como se tem do "comum acordo" para a propositura do dissídio coletivo econômico, tal qual o art. 114, $\S 2^{\circ}$ da Constituição ${ }^{25}$, modificado pela Emenda Constitucional ํo 45 .

Nessa mesma linha, a supressão imediata da contribuição sindical pela própria reforma trabalhista, sem qualquer escalonamento ou oportunidade de as entidades sindicais se adaptarem à uma nova realidade, com a modificação do do art. $578^{26}$ da CLT (vulnerabilizando os sindicatos nas suas condições de subsistência), somado a isso; a perda da especialidade do acordo coletivo em comparação com a convenção coletiva, em idêntica inversão de valores e finalidades ao até então assegurado mínimo civilizatório legal, com a alteração do conteúdo do art. 620 consolidado 27.

Ou seja, na prática a negociação coletiva, as convenções e os acordos coletivos de trabalho, continuam a ser formalmente procedimento e institutos relacionados ao Direito do Trabalho, montado em um contexto institucional de um

\footnotetext{
${ }^{25}$ Art. 114. Compete à Justiça do Trabalho processar e julgar: (...) $\S 2^{\circ}$ Recusando-se qualquer das partes à negociação coletiva ou à arbitragem, é facultado às mesmas, de comum acordo, ajuizar dissídio coletivo de natureza econômica, podendo a Justiça do Trabalho decidir o conflito, respeitadas as disposições mínimas legais de proteção ao trabalho, bem como as convencionadas anteriormente. ${ }^{26}$ Art. 578. As contribuições devidas aos sindicatos pelos participantes das categorias econômicas ou profissionais ou das profissões liberais representadas pelas referidas entidades serão, sob a denominação de contribuição sindical, pagas, recolhidas e aplicadas na forma estabelecida neste Capítulo, desde que prévia e expressamente autorizadas.

${ }^{27}$ Art. 620. As condições estabelecidas em acordo coletivo de trabalho sempre prevalecerão sobre as estipuladas em convenção coletiva de trabalho.
} 
Estado democrático ${ }^{28}$. Contudo, na prática servem como instrumento de legitimação da precarização das condições de trabalho e de vida, em nome de uma suposta liberdade negocial, em descompasso com as necessidades básicas essenciais asseguradas até então pela legislação geral e específica, uma verdadeira negação dos direitos fundamentais.

Fica assim evidente que os sindicatos não podem negociar direitos tradicionalmente indisponíveis dos seus representados, na forma exposta nos artigos 611-A e 661-B da CLT.

\section{REFERÊNCIAS}

AMARAL, Julio Ricardo de Paula. Eficácia dos Direitos Fundamentais nas Relações Trabalhistas, $2^{\mathrm{a}}$ edição, São Paulo, LTr, 2014.

ARIGÓN, Mario Garmendia. Orden Público y Derecho del Trabajo, 2ª edición, revisada, Ampliada y Actualizada, Montevideo, La Ley, 2016.

BARROSO, Fábio Túlio; MOURA, Felipe da Costa. A Negociação Coletiva como Instrumento de Efetividade do Direito do Trabalho e a Reforma Trabalhista Judicial. In: Direito Material e Processual do Trabalho, VI Congresso Latino-americano de Direito Material e Processual do Trabalho, Coordenado por Maria Cecília Máximo Teodoro, Márcio Túlio Viana, Cleber Lúcio de Almeida e Marcos Paulo da Silva Oliveira, São Paulo, LTr, 2018.

. Manual de Direito Coletivo do Trabalho. São Paulo, LTr, 2010.

BRASIL. CLT - Consolidação das Leis Trabalhistas. 1943.

Lei no 13.467, de Julho de 2017. Disponível em: http://www.planalto.gov.br/ccivil_03/_ato2015-2018/2017/lei//13467.htm.

Decreto-lei no 4.657, de 4 de setembro de 1942. Disponível em: http://www.planalto.gov.br/ccivil_03/decreto-lei/del4657compilado.htm.

28 "A montagem de instituições formais democráticas em seus processos permite divisões administrativas a serem feitas largamente independente de motivações específicas dos cidadãos. Isso ocorre através de um processo de legitimação que elide motivações generalizadas, isto é, difunde lealdade das massas, mas evita participação. Esta alteração estrutural do domínio público burguês, gera instituições e processos que são democráticos na forma, enquanto a cidadania, no meio de uma sociedade politicamente objetiva, gozar do status de cidadãos passivos, apenas com direito de embargar a aclamação" (HABERMAS, 2002, p.51). 
CAPARRÓS, Lucas; FERNÁNDEZ, Mariela. La Estructura de la Negociación Colectiva, la Economía y los Mercados. (Reflexiones sobre la Relación entre los Fatores Provenientes de la Economía y la Estructura de la Negociación Colectiva). In: El Derecho del Trabajo en Tiempos de Cambios, en Honor de Adrián Goldin, Coodenação de Fernando Caparrós, Héctor Omar García e Juan Pablo Mugnolo, Ediar, Buenos Aires, 2017.

CARRION, Valentin. Comentários à Consolidação das Leis do Trabalho, atualizado por Eduardo Carrion, 38ª edição, São Paulo, Saraiva, 2013.

DAL-RÉ, Fernando Valdés. La Negociación Colectiva, Entre Tradición y Renovación, Granada. Comares, 2012.

DELGADO, Maurício Godinho e DELGADO, Gabriela Neves. A Reforma Trabalhista no Brasil, com os Comentários à lei no 13.467/2017, LTr, São Paulo, 2017.

DOS SANTOS, Enoque Ribeiro. Direito Coletivo Moderno. Da LACP a do CDC ao Direito de Negociação coletiva no Setor Público, São Paulo, LTr, 2006.

DOS SANTOS, Ronaldo Lima. Teoria das Normas Coletivas. $2^{\mathrm{a}}$ edição, São Paulo, LTr, 2009.

GARCIA, Gustavo Felipe Barbosa. CLT Comentada, de Acordo com a Reforma Trabalhista. 4⿳亠丷厂 edição, revista, atualizada e ampliada, São Paulo, Gen/Método, 2018.

GUNTHER, Luiz Eduardo; VILLATORE, Marco Antônio César. Negociações Coletivas de Trabalho. As Decisões Judiciais e o Princípio da Fraternidade. Curitiba, Juruá, 2018.

MUGNOLO, Juan Pablo. Estuctura de la Negociación Colectiva. Influencia de la Intervención Estatal, Buenos Aires, Ediar, 2014.

NOGUEIRA, Hilda Maria Brzezinski da Cunha. A Reforma Trabalhista e o Negociado Sobre o Legislado. In: Reforma Trabalhista Ponto a Ponto. Estudos em Homenagem ao Professor Luiz Eduardo Gunther. Coordenação de José Affonso Dallegrave Neto e Ernani Kajota, São Paulo, Ltr, 2018.

OIT - Organização Internacional do Trabalho. C098 - Direito de Sindicalização e de Negociação Coletiva. 2018a. Disponível em: https://www.ilo.org/brasilia/temas/normas/WCMS 235188/lang--pt/index.htm. Acesso em 31 de agosto de 2018. 
. C154 - Fomento à Negociação Coletiva. 2018b. Disponível em:

https://www.ilo.org/brasilia/convencoes/WCMS 236162/lang--pt/index.htm. Acesso em: 31.ago.2018.

PÉREZ, José Luis Monereo, JIMÉNEZ, Natalia Tomás. Derecho a la Negociación Colectiva. In: El Sistema Universal de los Derechos Humanos, Estudio Sistemático de la Declaración Universal de los Derechos Humanos, el Pacto Internacional de Derechos Civiles y Políticos, el Pacto Internacional de Derechos Económicos, Sociales $y$ Culturales $y$ textos Internacionales Concordantes, Direção e Coordenação: ATIENZA, Cristina Monereo e PÉREZ, José Luis Monereo, Comares, Granada, 2014.

La Metamorfosis del Derecho del Trabajo, Bomarzo, Madrid, 2017.

SILVA, Sayonra Grillo Coutinho da. Relações Coletivas de Trabalho. Configurações Institucionais no Brasil Contemporâneo, LTr, São Paulo 2008.

TARELLO, Giovanni. Teorías e Ideologías em el Derecho Sindical. La Experiencia Italiana Después de la Consitución. Tradução e estudo preliminar "Cultura Jurídica y pluralismo jurídico-sindical em Giovanni Tarello" por José Luis Monereo Pérez, Comares, Granada, 2002.

TAVERES FILHO, Newton. Técnicas Legislativas. Disponível em: http://www2.camara.leg.br/a-camara/documentos-e-pesquisa/estudos-e-notastecnicas/copy_of_portas-abertas-1/Palestra\%208.pdf. Acesso em 27 de agosto de 2018.

JEAMMAUD, A. Les fonctions du Droit du Travail. In: Le Droit Capitaliste du Travail, F. COLLIN, R. DHOQUOIS, P.H. Goutierre, A. JEAMMAUD, G. LYONCAEN e A. ROUDIL. Presses Universitaires de Grenoble, Grenoble, 1980. 